\title{
Large mid-upper arm circumference is associated with metabolic syndrome in middle-aged and elderly individuals: a community-based study
}

Jie Shi ${ }^{1,2}$, Zhen Yang ${ }^{1,2^{*}}$ D, Yixin Niu ${ }^{1,2}$, Weiwei Zhang ${ }^{1}$, Xiaoyong $\mathrm{Li}^{1}$, Hongmei Zhang ${ }^{1}$, Ning Lin ${ }^{1}$, Hongxia Gu${ }^{2}$, Jie Wen ${ }^{3}$, Guang Ning ${ }^{4}$, Li Qin ${ }^{1,2^{*}}$ and Qing Su ${ }^{1,2^{*}}$

\begin{abstract}
Background: The mid-upper arm circumference (MUAC) is a proxy for subcutaneous fat in the upper body and is a reliable screening measure for identifying individuals with abnormal regional fat distribution. The purpose of this study was to evaluate the association between MUAC and metabolic syndrome (MetS) in middle-aged and elderly individuals.

Methods: We measured the MUAC in a cross-sectional sample with a total of 9787 subjects aged 40 years and older. The measurement of MUAC is performed on the right arm using a non-elastic tape held midway between the acromion and the olecranon processes in duplicate, with the arm hanging loosely at the side of the body. The MetS was defined according to the Joint Statement of the International Diabetes Federation Task Force on Epidemiology and Prevention.

Results: MUAC was positively correlated with waist circumference $(r=0.437, P<0.001), B M I(r=0.334, P<0.001)$, fasting insulin $(r=0.348, P<0.001)$, HOMA-IR $(r=0.134, P<0.001)$, triglycerides $(r=0.138, P<0.001)$, SBP $(r=0.124$, $P<0.001)$, and DBP $(r=0.123, P<0.001)$, and inversely correlated with adiponectin $(r=-0.147, P<0.001)$ and $\mathrm{HDL}$ cholesterol $(r=-0.176, P<0.001)$ after adjusting for age and gender. Compared with the lowest quartile group, the odds ratios were substantially higher for MetS $(\mathrm{OR} 1.77 ; 95 \% \mathrm{Cl} 1.51-2.09, \mathrm{P}$ for trend $<0.001)$ in the highest MUAC quartile group after adjustment for potential cofounder.
\end{abstract}

Conclusion: Large mid-upper arm circumference is significantly associated with metabolic syndrome in middleaged and elderly individuals.

Keywords: Metabolic syndrome, Mid-upper arm circumference, Central obesity, Subcutaneous fat

\footnotetext{
* Correspondence: yangzhen@xinhuamed.com.cn; qinli@xinhuamed.com.cn;

suqing@xinhuamed.com.cn

'Department of Endocrinology, Xinhua Hospital Chongming Branch,

Shanghai Jiaotong University School of Medicine, 25 Nanmen Road,

Shanghai 202150, China

Full list of author information is available at the end of the article
}

(c) The Author(s). 2020 Open Access This article is licensed under a Creative Commons Attribution 4.0 International License, which permits use, sharing, adaptation, distribution and reproduction in any medium or format, as long as you give appropriate credit to the original author(s) and the source, provide a link to the Creative Commons licence, and indicate if changes were made. The images or other third party material in this article are included in the article's Creative Commons licence, unless indicated otherwise in a credit line to the material. If material is not included in the article's Creative Commons licence and your intended use is not permitted by statutory regulation or exceeds the permitted use, you will need to obtain permission directly from the copyright holder. To view a copy of this licence, visit http://creativecommons.org/licenses/by/4.0/. The Creative Commons Public Domain Dedication waiver (http://creativecommons.org/publicdomain/zero/1.0/) applies to the data made available in this article, unless otherwise stated in a credit line to the data. 


\section{Background}

Metabolic syndrome (MetS), which contains a cluster of metabolic abnormalities including central obesity, hypertension, dysglycemia, and dyslipidemia that together culminate in the increased risk of cardiovascular disease (CVD) and diabetes, is a major global public health problem [1]. Of note, the prevalence of MetS is up to $30 \%$ in middle-aged and elderly people in China $[2,3]$. Given the continuous increase of the aging population in China, the high prevalence of MetS is a concerning observation that should be put on the agenda.

It is well established that different body fat distribution exist significant differences not only in free fatty acid (FFA) storage but also in FFA release [4]. Moreover, compared with the lower-body subcutaneous fat, the upper-body subcutaneous adipose tissue exhibited more active lipolysis [5, 6]. Numerous convincing evidence demonstrated that upper-body subcutaneous fat is significantly associated with increased visceral fat and involved in metabolic disorders independent of body mass indexes [7, 8]. Previous studies have revealed that systemic FFA is primarily derived from upper-body subcutaneous fat $[5,9]$, indicating that excessive upper arm fat depot may be a contributor to metabolic abnormality. On the one hand, the transfer of excess FFA from systemic adipose tissue lipolysis to liver tissue will result in excessive fat accumulation in the liver. On the other hand, elevated FFA levels also provoke VLDLtriglyceride production, insulin resistance, and inflammation, further increases the risk of metabolic disorders [10]. Furthermore, it has been demonstrated that dysregulation of fatty acid disposition, with ectopic lipid accumulation in non-adipose cells, is a major factor contributing to the development of MetS [11].

More recently, several studies have reported that midupper arm circumference (MUAC), a feasible and valid screening tool for identifying subjects with abnormal distribution of upper-body subcutaneous fat, was positively associated with higher risks of cardiometabolic disorders and subclinical atherosclerosis independent of waist circumference and BMI [12]. To date, however, much less is known about the relationship between MUAC and MetS among Chinese individuals. Thus, the purpose of this study was to evaluate the relationship between MUAC and MetS among Chinese middle-aged and elderly individuals.

\section{Methods}

\section{Study population}

The study is a part of the Risk Evaluation of cAncers in Chinese diabeTic Individuals: A lONgitudinal (REACTION) study, a community-based study conducted among 259,657 Chinese individuals aged 40 years and older [13]. REACTION study performed in 25 communities across mainland China, from 2011 to 2012. The study design and methods have been described previously in detail [13-15]. The data presented in this article are based on the baseline survey of subsamples from the Chongming District, Shanghai, China. A total of 9930 eligible subjects participated in the study. After excluding individuals with missing data about MUAC $(n=143), 9787$ subjects $(3156$ men and 6631 women) were eventually included in the present analysis. The study protocol was approved by the Ethics Committee of Xinhua Hospital Affiliated to Shanghai Jiaotong University School of Medicine. Written informed consent was obtained from all participants.

\section{Data collection}

A standardized questionnaire was applied by trained physicians to collect essential information, including sex, age, lifestyle factors, educational attainment, physical activity, and previous medical history. Anthropometric measurements were collected by certified physicians using standard protocols in duplicate base on the $\mathrm{Na}$ tional Health and Nutrition Examination Survey (NHANES) Anthropometry Procedures Manual [16]. The measurement of MUAC is performed on the right arm using a non-elastic tape held midway between the acromion and the olecranon processes, with the arm hanging loosely at the side of the body. Waist circumference was measured with a non-elastic tape held midway between the lower rib margin and the iliac crest at the end of a gentle expiration. Blood pressure (BP) was measured with an automated electronic device (OMRON Model1 Plus; Omron Company, Kyoto, Japan). Overweight was defined as body mass index (BMI) $\geq 24 \mathrm{~kg} /$ $\mathrm{m}^{2}$, central obesity was defined as waist circumference $\geq$ $85 \mathrm{~cm}$ for men and $\geq 80 \mathrm{~cm}$ for women.

\section{Biochemical measurements}

Peripheral venous blood samples were collected after an overnight fast for at least $10 \mathrm{~h}$. The plasma glucose level was measured by the glucose oxidase method (ADVIA1650 Chemistry System, Bayer, Leverkusen, Germany). We used an automatic analyzer (Hitachi 7080; Tokyo, Japan) to measured low-density lipoprotein (LDL) cholesterol, high-density lipoprotein (HDL) cholesterol, total cholesterol, and triglycerides. Hemoglobin A1c was determined by the HPLC method (BIO-RAD, D10, CA). Fasting insulin was measured by RIA (Linco Research, St. Charles, MO) and insulin resistance was evaluated using the homeostasis model of assessment for insulin resistance (HOMA-IR).

\section{Definition of MetS}

The MetS and metabolic risk factors were defined based on the Joint Statement of the World Heart Federation; National Heart, Lung, and Blood Institute; American 
Heart Association; International Diabetes Federation Task Force on Epidemiology and Prevention; International Atherosclerosis Society; and International Association for the Study of Obesity [1]. MetS was defined as having $\geq 3$ of the following metabolic risk factors: (1) central obesity (waist circumference $\geq 85 \mathrm{~cm}$ in men or $\geq$ $80 \mathrm{~cm}$ in women), (2) triglycerides $\geq 1.7 \mathrm{mmol} / \mathrm{L}$, (3) $\mathrm{HDL}$ cholesterol $<1.0 \mathrm{mmol} / \mathrm{L}$ in men or $<1.3 \mathrm{mmol} / \mathrm{L}$ in women, (4) systolic blood pressure (SBP) $\geq 130$ and/or diastolic blood pressure $(\mathrm{DBP}) \geq 85 \mathrm{mmHg}$ or current use of antihypertensive agents, (5) fasting plasma glucose $\geq 5.6 \mathrm{mmol} / \mathrm{L}$, previous diagnosis of type 2 diabetes or use of antidiabetic agents.

\section{Statistical analysis}

Continuous variables with normal distribution were expressed as means $\pm \mathrm{SD}$, variables with skewed distribution were shown as median (interquartile range) and log-transformed to approximate normality before analysis. Categorical variables were expressed by frequency and percentage. The subjects were divided into four groups according to the MUAC quartiles. For comparisons between groups, we performed one-way ANOVA for continuous variables with normal distributions and nonparametric tests for continuous variables with highly skewed distributions. The Chi-squared test was applied to compare categorical variables. Correlation coefficients between MUAC and metabolic features were calculated by partial correlation analysis after adjusted age and gender. Multivariate logistic regression analyses were used to test odds ratios (ORs) and 95\% confidence intervals (CIs) of Mets for each MUAC quartile compared with the lowest quartile (Q1) group. Model 1 was adjusted for age and gender; model 2 was adjusted for the variables in model 1 plus smoking, alcohol drinking, educational attainment, physical activity, and self-reported CVD; model 3 was adjusted for the variables in model 2 plus CRP, adiponectin, and HOMA-IR; model 4 was adjusted for the variables in model 3 plus BMI. Data management and statistical analysis were performed with SPSS (version 23.0). $\quad P<0.05$ was considered statistically significant.

\section{Results}

\section{Characteristics of participants according to MUAC quartiles}

The mean of MUAC was $29.24 \mathrm{~cm}$ for males and 28.41 $\mathrm{cm}$ for females $(P<0.001)$, respectively. The individuals were divided into four groups based on the quartiles of MUAC. When analyzed by quartiles of MUAC levels, as summarized in Table 1, the subjects with larger MUAC were more likely to be smokers, alcohol drinkers, and comorbidities including hypertension, hyperlipidemia, diabetes (all $P<0.05$ ). With regard to metabolic parameters, the individuals in the higher MUAC quartiles showed higher levels of SBP, DBP, BMI, waist circumference or waist-to-hip ratio, fasting glucose, insulin, HOMA-IR, CRP, triglycerides (all $P<0.001$ ), and LDL cholesterol $(P=0.003)$. Conversely, the subjects with larger MUAC displayed lower adiponectin and HDL cholesterol levels (both $\mathrm{P}<0.001$ ). However, elevated MUAC exhibited no association with the levels of total cholesterol in this study.

\section{Association between MUAC and MetS}

Partial correlation analysis showed that MUAC has the strongest correlation with waist circumference after adjusting for age and gender (Table 2). Additionally, MUAC was also strongly correlated with BMI and insulin.

The prevalence of MetS, overweight, and central obesity raised sharply from the small MUAC group to the large MUAC group both in men and women (All P for trend <0.001). In addition, women seem to have a higher prevalence of MetS and central obesity compared with men. Furthermore, with the accumulation of MetS components, MUAC was gradually increased both in males and females (Fig. 1). It is worth noting that as the components of MetS increased from none to five, the relationship between MUAC and MetS was statistically significant, both in subjects with Mets (number of MetS components $\geq 3$ ) and the subjects without MetS (number of MetS components <3). On this ground, MUAC may be directly or indirectly related to each MetS component.

As is shown in Table 3, the ORs for MetS and its components were significantly higher with increasing MUAC quartiles. In the largest MUAC quartile, the ORs (95\% CIs) were 5.71 (4.97-6.56) for MetS, 14.70 (12.49-17.31) for central obesity, 2.23 (1.90-2.62) for elevated triglycerides, 2.11 (1.86-2.40) for elevated blood pressure, 2.06 (1.79-2.37) for reduced HDL cholesterol, 1.54 (1.351.76) for elevated fasting glucose after adjusting for age, gender, smoking, alcohol consumption, educational attainment, physical activity, CRP, adiponectin, and selfreported CVD (referencing to 1.00) (Model 2, all P for trend <0.001). Further adjustment for HOMA-IR, CRP, and adiponectin, the OR was 3.24 (Model 3, 95\% CI 2.79-3.76, P for trend < 0.001) for MetS in the highest MUAC quartile. Moreover, the correlation between MUAC and MetS was still statistically significant by additional adjustment for BMI (Model 4, OR 1.77; 95\% CI 1.51-2.09; P for trend < 0.001).

\section{Discussion}

We observed a significant positive association between MUAC and MetS in a large-scale population study. Furthermore, we found that MUAC is strongly correlated 
Table 1 Characteristics of study participants according to MUAC quartiles

\begin{tabular}{|c|c|c|c|c|c|}
\hline \multirow[t]{2}{*}{ Characteristics } & Q1 $(n=2524)$ & Q2 $(n=2409)$ & $\mathrm{Q} 3(n=2427)$ & Q4 ( $n=2427)$ & \multirow{2}{*}{$\begin{array}{l}P \text { value } \\
\text { for } \\
\text { trend }\end{array}$} \\
\hline & $\leq 26.70$ & $26.71-28.60$ & $28.61-30.50$ & $\geq 30.51$ & \\
\hline MUAC (cm) & $24.93 \pm 1.53$ & $27.78 \pm 0.56$ & $29.61 \pm 0.53$ & $32.53 \pm 1.72$ & $<0.001$ \\
\hline Age (years) ${ }^{b}$ & $55.59 \pm 8.21$ & $56.06 \pm 7.81$ & $56.53 \pm 7.62$ & $56.47 \pm 7.59$ & $<0.001$ \\
\hline Male (\%) ${ }^{b}$ & 24.0 & 29.1 & 37.1 & 39.1 & $<0.001$ \\
\hline Smoking (yes, \%) & 14.3 & 17.2 & 18.1 & 19.9 & $<0.001$ \\
\hline Alcohol (yes, \%) & 18.1 & 24.5 & 26.0 & 28.1 & $<0.001$ \\
\hline \multicolumn{6}{|l|}{ Educational attainment (\%) } \\
\hline $0-6$ years & 20.7 & 21.7 & 21.8 & 25.4 & \multirow[t]{3}{*}{0.003} \\
\hline 7-9 years & 50.0 & 49.1 & 48.6 & 48.2 & \\
\hline$\geq 10$ years & 29.3 & 29.2 & 29.6 & 26.4 & \\
\hline \multicolumn{6}{|l|}{ Physical activity (\%) } \\
\hline Low & 70.8 & 72.5 & 71.6 & 72.2 & \multirow[t]{3}{*}{0.281} \\
\hline Moderate & 21.4 & 19.6 & 21.2 & 19.7 & \\
\hline High & 7.8 & 7.9 & 7.2 & 8.1 & \\
\hline $\mathrm{SBP}(\mathrm{mm} \mathrm{Hg})$ & $126.96 \pm 19.00$ & $129.72 \pm 18.42$ & $132.23 \pm 17.76$ & $134.55 \pm 18.94$ & $<0.001$ \\
\hline $\mathrm{DBP}(\mathrm{mm} \mathrm{Hg})$ & $79.02 \pm 9.51$ & $80.29 \pm 9.71$ & $81.13 \pm 9.50$ & $82.50 \pm 9.40$ & $<0.001$ \\
\hline BMI $\left(\mathrm{kg} / \mathrm{m}^{2}\right)$ & $22.79 \pm 2.90$ & $24.47 \pm 2.48$ & $25.46 \pm 2.61$ & $26.94 \pm 3.08$ & $<0.001$ \\
\hline Waist circumference (cm) & $78.38 \pm 11.41$ & $82.94 \pm 8.49$ & $86.54 \pm 8.75$ & $91.11 \pm 8.77$ & $<0.001$ \\
\hline Waist to hip ratio & $0.86 \pm 0.08$ & $0.87 \pm 0.09$ & $0.89 \pm 0.17$ & $0.90 \pm 0.07$ & $<0.001$ \\
\hline Fasting glucose (mmol/L) & $6.20 \pm 1.82$ & $6.23 \pm 1.73$ & $6.33 \pm 1.65$ & $6.38 \pm 1.52$ & $<0.001$ \\
\hline 2-h glucose (mmol/L) & $8.30 \pm 4.01$ & $8.61 \pm 3.94$ & $8.91 \pm 3.79$ & $9.18 \pm 3.73$ & $<0.001$ \\
\hline Insulin $(\mathrm{mU} / \mathrm{L})^{\mathrm{c}}$ & $6.25(3.90-7.20)$ & $7.18(4.50-8.50)$ & $7.75(5.20-9.20)$ & $9.40(6.10-11.50)$ & $<0.001$ \\
\hline HOMA-IR ${ }^{c}$ & $1.70(0.98-1.99)$ & $2.00(1.22-2.45)$ & $2.22(1.38-2.68)$ & $2.70(1.65-3.38)$ & $<0.001$ \\
\hline CRP (ug/ml) & $4.79 \pm 5.74$ & $4.94 \pm 5.85$ & $5.13 \pm 6.12$ & $5.24 \pm 6.27$ & $<0.001$ \\
\hline Adiponectin (ug/ml) & $12.34(7.92-15.67)$ & $10.93(6.72-13.15)$ & $8.17(5.24-11.33)$ & $6.29(4.78-9.75)$ & $<0.001$ \\
\hline Triglycerides $(\mathrm{mmol} / \mathrm{L})^{c}$ & $1.44(0.83-1.66)$ & $1.67(0.94-1.94)$ & $1.83(1.03-2.13)$ & $1.96(1.12-2.34)$ & $<0.001$ \\
\hline Total cholesterol (mmol/L) & $4.64 \pm 1.05$ & $4.62 \pm 1.03$ & $4.65 \pm 1.04$ & $4.67 \pm 1.03$ & 0.291 \\
\hline LDL cholesterol (mmol/L) & $2.58 \pm 0.78$ & $2.59 \pm 0.76$ & $2.63 \pm 0.77$ & $2.65 \pm 0.76$ & 0.003 \\
\hline HDL cholesterol (mmol/L) & $1.32 \pm 0.34$ & $1.23 \pm 0.32$ & $1.19 \pm 0.30$ & $1.16 \pm 0.28$ & $<0.001$ \\
\hline \multicolumn{6}{|l|}{ Comorbidities (\%) } \\
\hline Hypertension & 20.8 & 25.0 & 31.4 & 36.9 & $<0.001$ \\
\hline Hyperlipidemia & 2.8 & 3.4 & 5.8 & 6.2 & $<0.001$ \\
\hline Diabetes & 8.8 & 9.3 & 10.8 & 10.8 & 0.036 \\
\hline$C V D^{d}$ & 2.6 & 3.9 & 3.2 & 4.1 & 0.014 \\
\hline
\end{tabular}

${ }^{a}$ Data are means \pm SD, median (interquartile range), or percentage; P value was calculated after adjustment for age and gender. ${ }^{\mathrm{b}}$ Not adjusted for itself. ${ }^{\mathrm{c}}$ These variables were log transformed before analysis. ${ }^{d}$ Self-reported CVD including stroke and coronary heart disease

with waist circumference, lipid parameters, blood pressure, and insulin, which indicated that abnormal local fat depot is a potential screening index for identifying metabolic disorders.

BMI and waist circumference are common screening measures for identifying individuals with abnormal distribution of body fat. Nevertheless, BMI cannot provide accurate information about the local distribution of body fat and it is difficult to obtain height and weight for patients who cannot stand. As for waist circumference, the deficiency of daily application lies in the big difference between preprandial and postprandial measurements. In view of the above reasons, MUAC began to show diagnostic value for assessing nutritional status. Compared to other anthropometric measurements, MUAC is not only easier to obtain, but also has other advantages such as being more accurate, convenient, and low-cost. Small MUAC has shown excellent performance in assessing malnutrition and predicting mortality both 
Table 2 Partial correlation coefficients among MUAC and other clinical parameters

\begin{tabular}{lll}
\hline Variable & MUAC & \\
\cline { 2 - 3 } & $r$ & $P$ \\
\hline BMI & 0.334 & $<0.001$ \\
Waist circumference & 0.437 & $<0.001$ \\
SBP & 0.124 & $<0.001$ \\
DBP & 0.123 & $<0.001$ \\
Fasting plasma glucose & 0.045 & 0.043 \\
2-h post-loading glucose & 0.074 & $<0.001$ \\
Insulin & 0.348 & $<0.001$ \\
HOMA-IR & 0.134 & $<0.001$ \\
CRP & 0.110 & 0.008 \\
Adiponectin & -0.147 & $<0.001$ \\
HDL cholesterol & -0.176 & $<0.001$ \\
LDL cholesterol & 0.024 & 0.016 \\
Triglycerides & 0.138 & $<0.001$ \\
\hline All corretion coeficients were &
\end{tabular}

All correlation coefficients were calculated after adjustment for age and gender

in children [17] and older individuals [18, 19]. More recently, large MUAC has been recognized as a valid tool for detecting overweight and obesity in children and adolescents $[20,21]$. However, the study about whether MUAC is associated with obesity-related metabolic abnormality, such as MetS, is scarce. Currently, we found that MUAC, as a proxy of upper-body subcutaneous adipose, was positively associated with MetS. Moreover, consistent with previous studies [12], we found large MUAC also tightly correlated with central obesity, elevated blood pressure, and low HDL cholesterol.

The abnormal accumulation of fat affects adipose tissue metabolic capacities, endocrine, and immune function and leads to altered production of lipid mediators, adipokines, pro- or anti-inflammatory cytokines, and impaired signaling pathways that contribute to obesityrelated metabolic abnormality [22]. Obesity increases the flux of fatty acids from adipose tissue to peripheral tissues [23]. The increase in FFAs derived from adipose tissue is mainly mediated by the resistance of adipose tissue to the anti-lipolytic action of insulin [24]. There is compelling evidence that abnormally increased visceral fat is a maker of excessive systemic FFAs release [25], but it is worth noting that it is upper-body subcutaneous fat released the majority of FFAs [26]. Large MUAC means excessive subcutaneous fat accumulation, which contributes a greater portion of the fatty acids released into the circulation. Circulating FFAs is a crucial mediator in the development of metabolic disorders [27]. Elevated plasma FFAs induce insulin resistance, inflammation, and increase the synthesis and ectopic deposition of triglycerides [28-31]. Concomitantly, excessive FFAs also affect glucose metabolism by inhibiting glucose uptake, oxidation, glycogen synthesis, and increasing output hepatic glucose [32]. Additionally, increased FFAs can trigger oxidative stress which is an early instigator of MetS [33], and endoplasmic reticulum stress which intersects with many different inflammatory and stress signaling pathways by unfolded protein response [34-36]. The excess FFAs release derived from excess accumulation of arm subcutaneous adipose might be a potential mechanism to partly explain the correlation between MUAC and MetS.

Moreover, the adipose tissue is not only a depot of excess energy but also a highly active metabolic endocrine organ that secretes numerous biologically active molecules, which are collectively termed adipokines [37]. When adipose tissue expands, the capacity of adipocytes to function as endocrine cells and secrete various adipokines is altered in individuals with obesity and MetS [33, 38]. These abnormal levels of adipokine are linked to insulin resistance, impaired

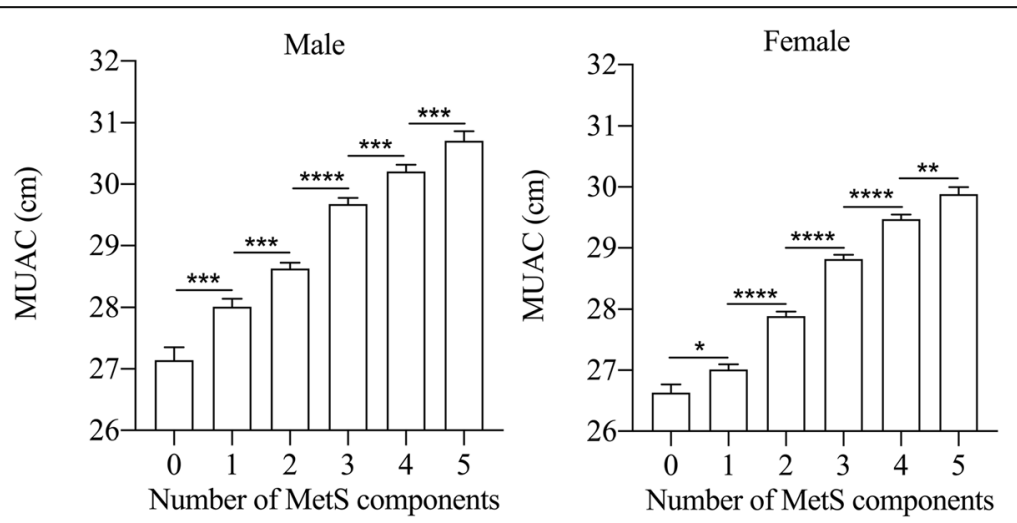

Fig. 1 MUAC according to the number of MetS components. Data are shown as the means \pm SEM. The mean values of MUAC for those with none to five components were 27.14, 28.01, 28.63, 29.70, 30.21, $30.71 \mathrm{~cm}$ for males, and 26.62, 27.00, 27.83, 28.79, 29.43, $29.8 \mathrm{~cm}$ for females, respectively. *: $P<0.05 ;{ }^{* *}: P<0.01$; **: $P<0.001$; ***: $P<0.0001$. MUAC, mid-upper arm circumference; MetS, metabolic syndrome 
Table 3 Adjusted ORs (95\% Cl) of MetS and its components according to the quartiles of MUAC

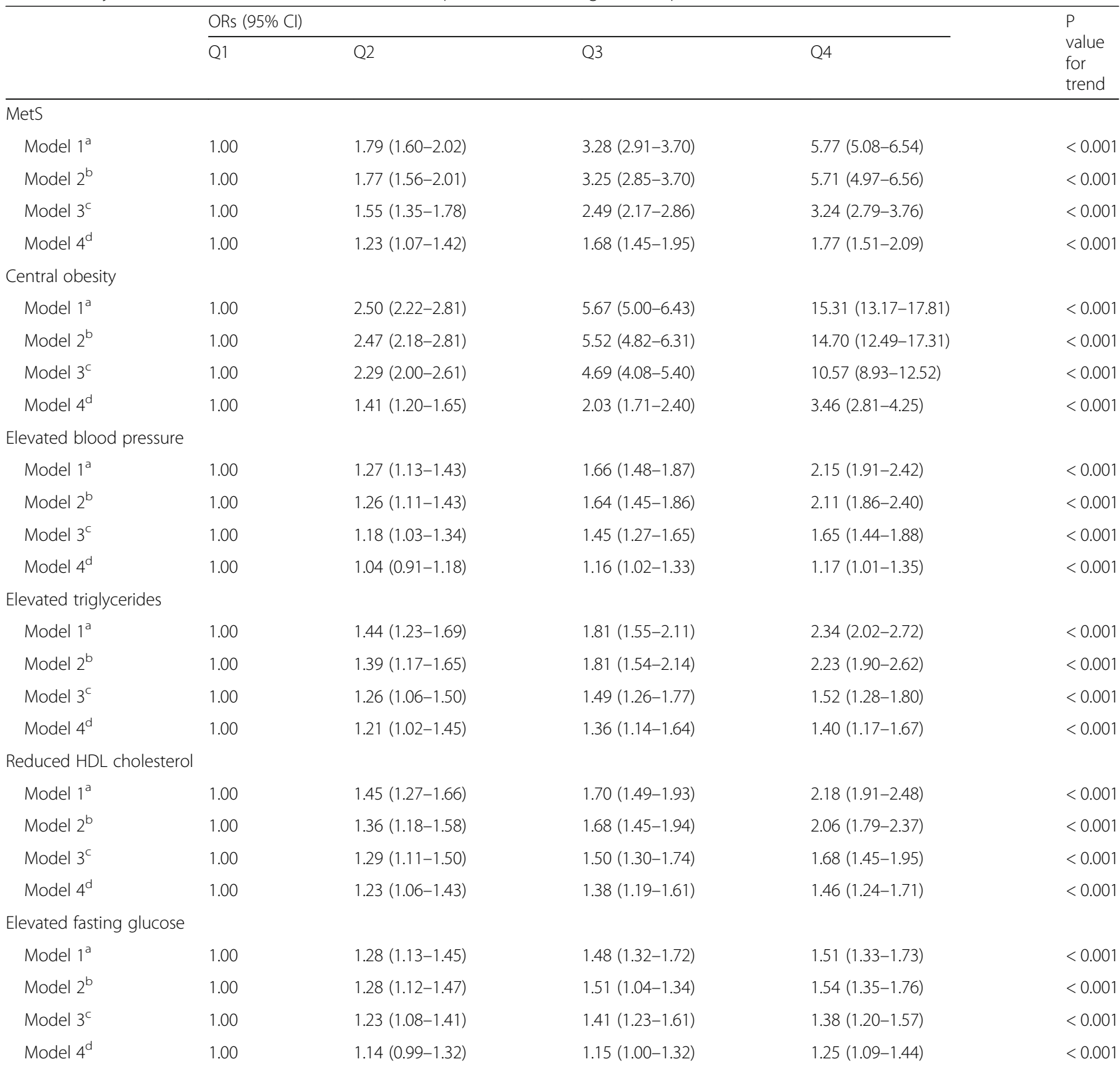

${ }^{\mathrm{a}}$ Model 1 was adjusted for age and gender. ${ }^{\mathrm{b}}$ Model 2 was further adjusted for smoking, alcohol drinking, educational attainment, physical activity, and selfreported CVD. ${ }^{c}$ Model 3 was further adjusted for CRP, adiponectin, and HOMA-IR. ${ }^{d}$ Model 4 was further adjusted for BMI. Q, quartile. Q1 is the reference group. Multivariate logistic regression models were used to estimate the odds ratios (ORs) with corresponding $95 \%$ confidence intervals (Cls) for MetS and its components. The final model is statistically significant $\left(X^{2}=34.927, P<0.001\right)$

triglyceride storage and increased fatty acids in circulation [39]. Furthermore, as fat accumulation, substantial infiltration of immune cells occurs, and there is a specific crown-like disposition of macrophages around single necrotic adipocytes in obese people [40] and subjects with MetS [38]. Subsequently, proinflammatory pathways were activated, and certain proinflammatory cytokines and chemokines were overflowed that result in low-grade inflammation and insulin resistance [22, 38]. In line with the previous study [12], our findings also observed that MUAC is positively correlated with CRP. Overall, adipose dysfunctions, inflammation, and stress linking mid-upper arm obesity to insulin resistance and MetS.

To our knowledge, this is the first study to evaluate the association between MUAC and Mets among large-scale middle-aged and older people. The major strength of this study is the analysis based on a large sample. Potential covariates were strictly controlled in the analysis, so as to eliminated the possibility of residual confounding effects. 
This study has several limitations. For one thing, we did not measure the tissue composition of the midupper arm. The use of MUAC to evaluate the midupper arm subcutaneous fat was a convenient and practical way but was unable to quantify the fat accumulation. Therefore, the amount and size of subcutaneous adipocyte and muscle fat are not clear. For another, due to the present study is a cross-sectional analysis, we cannot draw the causality from our findings. Additionally, it is still unclear whether our findings in middle-aged/older Chinese subjects can be generalized to younger populations or individuals of other ethnicities.

In brief, our study observed that MUAC is positively associated with MetS even after adjustment for potential covariates. These findings provide a novel insight into the association between upper-body obesity and MetS, and a potential screening tool for identifying individuals with MetS. Further researches are necessary to explore the underlying pathophysiological mechanism of the relationship between mid-upper arm subcutaneous fat and MetS.

\section{Conclusion}

In summary, in this population-based study, there is a significantly positive association between MUAC and MetS in Chinese middle-aged and elderly individuals. Our results indicated that MUAC in the routine clinical measurement is necessary to screen for metabolic disorders, including dyslipidemia, dysglycemia, and elevated blood pressure.

\begin{abstract}
Abbreviations
MUAC: Mid-upper arm circumference; MetS: Metabolic syndrome; FFAs: Free fatty acids; BMI: Body mass index; HDL: High-density lipoprotein; LDL: Lowdensity lipoprotein; CVD: Cardiovascular disease; T2D: Type 2 diabetes; HOMA-IR: Homeostasis model of assessment for insulin resistance; SBP: Systolic blood pressure; DBP: Diastolic blood pressure; OR: Odds ratios; Cl: Confidence interval; CRP: C-reactive protein; SD: Standard deviation
\end{abstract}

\section{Acknowledgments}

The authors thank all subjects who participated in the study and hospital staff for their contribution in sample and data collection.

\section{Authors'contributions}

$Z Y, L Q$, and $Q S$ designed the study. YN, WZ, XL, HZ, NL, HG, JW, and GN recruited the subjects, processed samples, and contributed to the acquisition of data. JS and ZY analyzed the data. JS wrote the manuscript. ZY revised the manuscript. All authors have read and approved the final manuscript.

\section{Funding}

This work was supported by the National Natural Science Foundation of China (81670743, 81370953), Shanghai Health System Outstanding Young Talents Training Program (XYQ2013098), Shanghai Health and Family Planning Commission (21740173). The funding body had no role in the design of the study and collection, analysis, and interpretation of data and in writing the manuscript.

\section{Availability of data and materials}

All data generated and analyzed during the current study are included in the REACTION study. The data that support the findings of this study are available from the corresponding author on reasonable request. Inquiries for data access may be sent to the following e-mail address: yangzhen@xinhuamed.com.cn.

\section{Ethics approval and consent to participate}

All procedures performed in this study involving human participants have been approved by the Ethics Committee of the Xinhua Hospital Affiliated to Shanghai Jiaotong University School of Medicine and performed in accordance with the 1964 Helsinki Declaration and its later amendments or comparable ethical standards. Written informed consent was obtained from all the respondents.

\section{Consent for publication}

This manuscript does not report personal data such as individual details, images or videos; therefore, consent for publication is not applicable.

\section{Competing interests}

The authors declare that they have no competing interests.

\section{Author details}

'Department of Endocrinology, Xinhua Hospital Chongming Branch, Shanghai Jiaotong University School of Medicine, 25 Nanmen Road, Shanghai 202150, China. ${ }^{2}$ Department of Endocrinology, Xinhua Hospital, Shanghai Jiaotong University School of Medicine, Shanghai 200092, China. ${ }^{3}$ Institute of Endocrinology and Diabetes, Department of Endocrinology and Metabolism, Huashan Hospital, Fudan University, Shanghai 200040, China.

${ }^{4}$ Shanghai Institute of Endocrinology and Metabolism, Department of Endocrine and Metabolic Diseases, Shanghai Clinical Center for Endocrine and Metabolic Diseases, Ruijin Hospital, Shanghai Jiaotong University School of Medicine, Shanghai 200025, China.

Received: 1 October 2019 Accepted: 25 May 2020

Published online: 03 June 2020

\section{References}

1. Alberti KG, Eckel RH, Grundy SM, Zimmet PZ, Cleeman Jl, Donato KA, Fruchart JC, James WP, Loria CM, Smith SC Jr. Harmonizing the metabolic syndrome: a joint interim statement of the international diabetes federation task force on epidemiology and prevention; National Heart, Lung, and Blood Institute; American Heart Association; world heart federation; international atherosclerosis society; and International Association for the Study of obesity. Circulation. 2009;120(16):1640-5.

2. Gu D, Reynolds K, Wu X, Chen J, Duan X, Reynolds RF, Whelton PK, He J. Prevalence of the metabolic syndrome and overweight among adults in China. Lancet. 2005;365(9468):1398-405.

3. He Y, Jiang B, Wang J, Feng K, Chang Q, Fan L, Li X, Hu FB. Prevalence of the metabolic syndrome and its relation to cardiovascular disease in an elderly Chinese population. J Am Coll Cardiol. 2006;47(8):1588-94.

4. Koutsari C, Ali AH, Mundi MS, Jensen MD. Storage of circulating free fatty acid in adipose tissue of postabsorptive humans: quantitative measures and implications for body fat distribution. Diabetes. 2011;60(8):2032-40.

5. Nielsen S, Guo Z, Johnson CM, Hensrud DD, Jensen MD. Splanchnic lipolysis in human obesity. J Clin Invest. 2004;113(11):1582-8.

6. Basu A, Basu R, Shah P, Vella A, Rizza RA, Jensen MD. Systemic and regional free fatty acid metabolism in type 2 diabetes. Am J Physiol Endocrinol Metab. 2001;280(6):E1000-6.

7. Liang J, Teng F, Li Y, Liu X, Zou C, Wang Y, Li H. Qi L: neck circumference and insulin resistance in Chinese adults: the Cardiometabolic risk in Chinese (CRC) study. Diabetes Care. 2013;36(9):e145-6.

8. Yang G-R, Yuan S-Y, Fu H-J, Wan G, Zhu L-X, Bu X-L, Zhang J-D, Du X-P, Li $Y$-L, Ji $Y$, et al. Neck circumference positively related with central obesity, overweight, and metabolic syndrome in Chinese subjects with type 2 diabetes: Beijing community diabetes study 4. Diabetes Care. 2010;33(11): 2465-7.

9. Jensen MD. Role of body fat distribution and the metabolic complications of obesity. J Clin Endocrinol Metab. 2008;93(11 Suppl 1):S57-63.

10. Boden G. Fatty acid-induced inflammation and insulin resistance in skeletal muscle and liver. Curr Diab Rep. 2006:6(3):177-81.

11. Berk PD. Regulatable fatty acid transport mechanisms are central to the pathophysiology of obesity, fatty liver, and metabolic syndrome. Hepatology. 2008;48(5):1362-76.

12. Hou Y, Jia X, Xuan L, Zhu W, Deng C, Wang L, Zhao Z, Li M, Lu J, Xu Y, et al. Association between mid-upper arm circumference and cardiometabolic risk in Chinese population: a cross-sectional study. BMJ Open. 2019:9(9): e028904. 
13. Ning G. Risk evaluation of cAncers in Chinese diabeTic individuals: a IONgitudinal (REACTION) study. J Diabetes. 2012;4(2):172-3.

14. Yang Z, Yan C, Liu G, Niu Y, Zhang W, Lu S, Li X, Zhang H, Ning G, Fan J, et al. Plasma selenium levels and nonalcoholic fatty liver disease in Chinese adults: a cross-sectional analysis. Sci Rep. 2016;6:37288.

15. Qin L, Yang Z, Gu H, Lu S, Shi Q, Xing Y, Li X, Li R, Ning G, Su Q. Association between serum uric acid levels and cardiovascular disease in middle-aged and elderly Chinese individuals. BMC Cardiovasc Disord. 2014;14:26.

16. Anthropometry Procedures Manual .pdf.

17. Berkley J, Mwangi I, Griffiths K, Ahmed I, Mithwani S, English M, Newton C, Maitland K. Assessment of severe malnutrition among hospitalized children in rural Kenya: comparison of weight for height and mid upper arm circumference. Jama. 2005;294(5):591-7.

18. Schaap LA, Quirke T, Wijnhoven HAH, Visser M: Changes in body mass index and mid-upper arm circumference in relation to all-cause mortality in older adults. Clin Nutr 2018, 37(6 Pt A):2252-2259.

19. Wijnhoven HA, van Bokhorst-de van der Schueren MA, Heymans MW, de Vet HC, Kruizenga HM, Twisk JW, Visser M. Low mid-upper arm circumference, calf circumference, and body mass index and mortality in older persons. J Gerontol A Biol Sci Med Sci. 2010;65(10):1107-14.

20. Talma H, van Dommelen P, Schweizer JJ, Bakker B, Kist-van Holthe JE, Chinapaw JMM, Hirasing RA. Is mid-upper arm circumference in Dutch children useful in identifying obesity? Arch Dis Child. 2019;104(2):159-65.

21. Chaput JP, Katzmarzyk PT, Barnes JD, Fogelholm M, Hu G, Kuriyan R, Kurpad A, Lambert EV, Maher C, Maia J, et al. Mid-upper arm circumference as a screening tool for identifying children with obesity: a 12-country study. Pediatr Obes. 2017;12(6):439-45.

22. Weisberg SP, McCann D, Desai M, Rosenbaum M, Leibel RL, Ferrante AW Jr. Obesity is associated with macrophage accumulation in adipose tissue. $J$ Clin Invest. 2003;112(12):1796-808.

23. Arner $P$, Langin D. Lipolysis in lipid turnover, cancer cachexia, and obesityinduced insulin resistance. Trends Endocrinol Metab. 2014;25(5):255-62.

24. Saltiel AR, Kahn CR. Insulin signalling and the regulation of glucose and lipid metabolism. Nature. 2001;414(6865):799-806.

25. Guo Z, Hensrud DD, Johnson CM, Jensen MD. Regional postprandial fatty acid metabolism in different obesity phenotypes. Diabetes. 1999;48(8):1586-92.

26. Martin ML, Jensen MD. Effects of body fat distribution on regional lipolysis in obesity. J Clin Invest. 1991;88(2):609-13.

27. Boden G. Obesity, insulin resistance and free fatty acids. Curr Opin Endocrinol Diabetes Obes. 2011;18(2):139-43.

28. Kim F, Pham M, Luttrell I, Bannerman DD, Tupper J, Thaler J, Hawn TR, Raines EW, Schwartz MW. Toll-like receptor-4 mediates vascular inflammation and insulin resistance in diet-induced obesity. Circ Res. 2007;100(11):1589-96.

29. Shi H, Kokoeva MV, Inouye K, Tzameli I, Yin H, Flier JS. TLR4 links innate immunity and fatty acid-induced insulin resistance. J Clin Invest. 2006; 116(11):3015-25.

30. Morino K, Petersen KF, Shulman Gl. Molecular mechanisms of insulin resistance in humans and their potential links with mitochondrial dysfunction. Diabetes. 2006;55(Suppl 2):S9-s15.

31. Hotamisligil GS. Inflammation, metaflammation and immunometabolic disorders. Nature. 2017:542(7640):177-85.

32. Bergman RN, Ader M. Free fatty acids and pathogenesis of type 2 diabetes mellitus. Trends Endocrinol Metab. 2000;11(9):351-6.

33. Furukawa S, Fujita T, Shimabukuro M, Iwaki M, Yamada Y, Nakajima Y, Nakayama O, Makishima M, Matsuda M, Shimomura I. Increased oxidative stress in obesity and its impact on metabolic syndrome. J Clin Invest. 2004; 114(12):1752-61.

34. Guo W, Wong S, Xie W, Lei T, Luo Z. Palmitate modulates intracellular signaling, induces endoplasmic reticulum stress, and causes apoptosis in mouse 3T3-L1 and rat primary preadipocytes. Am J Physiol Endocrinol Metab. 2007;293(2):E576-86.

35. Ozcan U, Cao Q, Yilmaz E, Lee AH, Iwakoshi NN, Ozdelen E, Tuncman G, Gorgun C, Glimcher LH, Hotamisligil GS. Endoplasmic reticulum stress links obesity, insulin action, and type 2 diabetes. Science. 2004;306(5695):457-61.

36. Hotamisligil GS. Endoplasmic reticulum stress and the inflammatory basis of metabolic disease. Cell. 2010;140(6):900-17.

37. Kershaw EE, Flier JS. Adipose tissue as an endocrine organ. J Clin Endocrinol Metab. 2004;89(6):2548-56.

38. Bremer AA, Devaraj S, Afify A, Jialal I. Adipose tissue dysregulation in patients with metabolic syndrome. J Clin Endocrinol Metab. 2011; 96(11):E1782-8
39. Guilherme A, Virbasius JV, Puri V, Czech MP. Adipocyte dysfunctions linking obesity to insulin resistance and type 2 diabetes. Nat Rev Mol Cell Biol. 2008;9(5):367-77.

40. Cancello R, Henegar C, Viguerie N, Taleb S, Poitou C, Rouault C, Coupaye M, Pelloux $V$, Hugol D, Bouillot $J$, et al. Reduction of macrophage infiltration and chemoattractant gene expression changes in white adipose tissue of morbidly obese subjects after surgery-induced weight loss. Diabetes. 2005; 54(8):2277-86.

\section{Publisher's Note}

Springer Nature remains neutral with regard to jurisdictional claims in published maps and institutional affiliations.

\section{Ready to submit your research? Choose BMC and benefit from:}

- fast, convenient online submission

- thorough peer review by experienced researchers in your field

- rapid publication on acceptance

- support for research data, including large and complex data types

- gold Open Access which fosters wider collaboration and increased citations

- maximum visibility for your research: over $100 \mathrm{M}$ website views per year

At BMC, research is always in progress.

Learn more biomedcentral.com/submissions 